\title{
The mating system and genetic structure in a perennial grass, Cynosurus cristatus L.
}

\author{
R. A. Ennos*
}

\author{
Genetics Department, University of Newcastle upon \\ Tyne, Claremont Place, Newcastle upon Tyne \\ NE1 7RU.
}

The breeding system, genotypic structure, and degree of spatial genetic differentiation were investigated in a population of the perennial grass Cynosurus cristatus using four polymorphic allozyme loci. Both incompatability studies and analysis of progeny genotype arrays gave outcrossing rate estimates of $t=0.98$, not significantly different from random mating. Levels of inbreeding and of gametic disequilibrium between allozyme loci were negligible. Genetic differentiation among adult subpopulations was very low $\left(G_{S T}=1 \cdot 14\right.$ per cent $)$. Among pollen pool subpopulations genetic differentiation was even lower $\left(G_{S T}=0.28\right.$ per cent). It is concluded that substantial pollen flow prevents the development of significant genetic differentiation through random genetic drift in different areas of the same population.

\section{INTRODUCTION}

Local genetic differentiation in response to selection has been studied extensively in populations of perennial, wind pollinated, outcrossing grasses (Jain and Bradshaw, 1966; McNeilly, 1968; Snaydon and Davies, 1972). Less attention has been paid, however, to the amount of genetic differentiation which arises in such populations in the absence of selection. When gene flow is restricted within a continuous population, genetic divergence may occur among different areas of the population through random genetic drift (Wright, 1943; Rohlf and Schnell, 1971; Turner et al., 1982; Crawford, 1984). Analysis of microgeographic differentiation at allozyme loci has provided evidence that such genetic divergence occurs in insect pollinated and inbreeding species (Schaal, 1974; Brown, 1979). Few data are available for outcrossing grasses.

Gene flow within populations, occurring principally through pollen dispersal, is expected to be greater for outcrossing wind pollinated species than for insect pollinated or inbreeding plants.

\footnotetext{
* Present address: Department of Forestry and Natural Resources, University of Edinburgh, Darwin Building, King's Buildings, Edinburgh EH9 3JU.
}

This reduces the likelihood that genetic differentiation will occur through drift. However, pollen dispersal by wind may not be as extensive in natural populations of grasses as experimental measurements predict (Gleaves, 1973). There may still be the opportunity for significant genetic differentiation to occur by chance.

The extent of such differentiation was investigated by studying the spatial heterogeneity in allozyme frequencies within a natural population of the grass Cynosurus cristatus. This was combined with an analysis of the mating system and genotypic structure of the population using allozyme markers to build up a picture of the arrangement of genetic variation within this outcrossed, wind pollinated species.

\section{MATERIALS AND METHODS}

Cynosurus cristatus, crested dogstail, is a compact diploid, perennial grass found as a common component of pastures of moderate fertility in Britain. The species is outcrossing and wind pollinated, producing a tough, wiry flower stem which is unpalatable to stock. This enables the plant to flower freely even under heavy grazing. 
The study site was a permanent pasture grazed by sheep and cattle, located 10 miles north of Newcastle upon Tyne. The land had not been ploughed within living memory, and no obvious ecological differences or gradients were apparent within the pasture. Flower heads of C. cristatus were found at a density of 78 heads $/ \mathrm{m}^{2}$ during the flowering season (July-September) in association with Lolium perenne, Agrostis tenuis, Anthoxanthum odoratum, Holcus lanatus, Trifolium repens and $T$. pratense.

In late August 1982100 mature seed heads and their associated maternal tillers were sampled at $1 \mathrm{~m}$ intervals from each of three $10 \times 10 \mathrm{~m}$ subpopulations. Subpopulations were located within the pasture at the apices of a triangle measuring $100 \times 200 \times 100 \mathrm{~m}$. Tillers were rooted and grown for 3 months in a cool greenhouse. Fifteen seeds from the first 50 seed heads collected in each subpopulation were germinated and grown by family in seed trays.

Starch gel electrophoresis was carried out using standard techniques on crude extracts from fresh meristematic stem tissue. Each maternal tiller and eleven of the fifteen progeny germinated per seed head were scored for their genotype at four diallelic allozyme loci, MDH1, MDH2, ADH and GOT. These loci show regular Mendelian inheritance. $\mathrm{MDH} 1$ and $\mathrm{MDH} 2$ are loosely linked, recombination fraction $r=0.36$ (for full details see Ennos, 1985).

After electrophoretic analysis, maternal genotypes were transferred to a sand bed outside to venalise. When flower spikes emerged in June 1983, 24 pair crosses were conducted by bagging together heads from different maternal genotypes. 147 plants were bagged alone to measure seed set under self-pollination. Other plants were left unbagged to measured open pollinated seed set. When seeds were mature, seed set per mm spike length was recorded for each plant and treatment.

\section{RESULTS}

\section{(i) Incompatibility}

Mean seed set in pair crosses was far higher than in self pollinations ( 1.568 vs. 0.022 seeds $/ \mathrm{mm}$ spike length) and there was no overlap between the two distributions (fig. 1). Bagging had no detrimental effect on seed set; indeed bagged pair crosses gave greater mean seed set than flower heads which were open pollinated in the greenhouse.

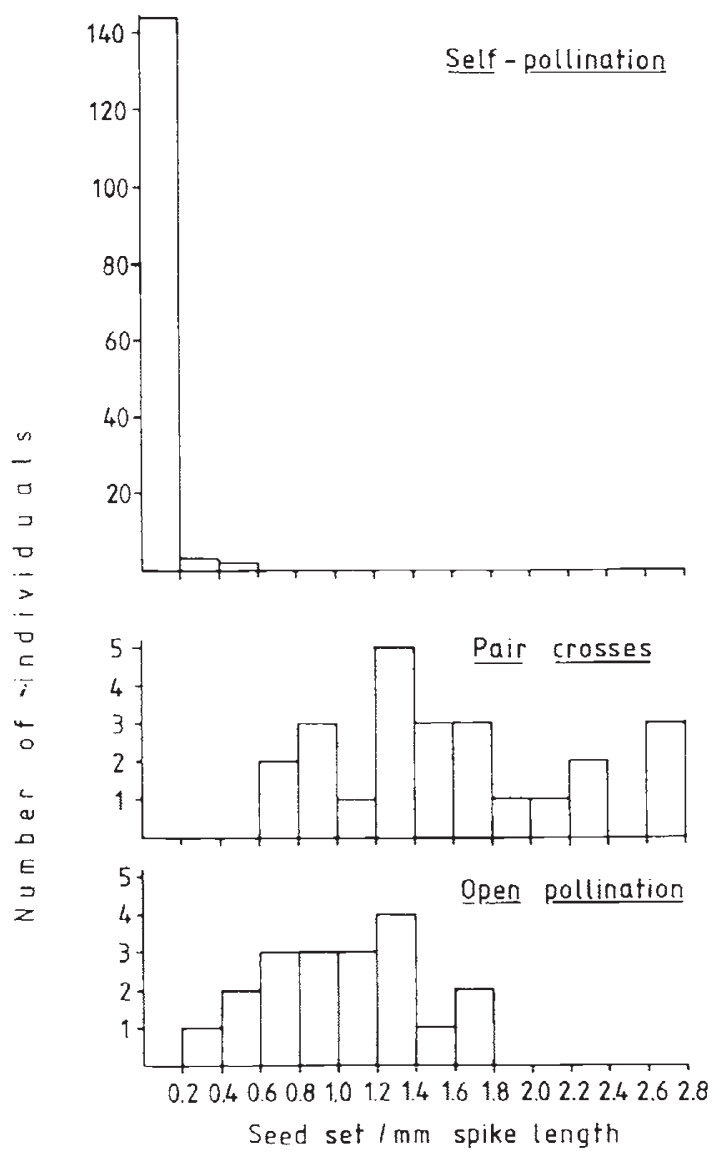

Figure 1 Distributions of seed set/mm spike length under self-pollination, pair crosses, and open pollination.

Inability to set seed under self pollination is likely to be due to a self incompatability system rather than dichogamy because pollen is shed and stigmas are exerted simultaneously. Moreoever inclusion of heads at different developmental stages in the same bag did not enhance seed set under self pollination.

Pair crosses measure seed set by outcrossing and self fertilisation, whereas genotypes bagged alone gave an estimate of seed set through selffertilisation. From these two figures the proportion of outcrossed seed expected under the incompatability system can be calculated. If the incompatability system is the only determinant of the mating system, outcrossing rate is expected to be $t=0.985$ in the natural population.

\section{(ii) Outcrossing rate}

Data on progeny genotype arrays derived from known maternal genotypes were used to estimate 
Table 1 Single locus and multilocus estimates of outcrossing rate $t$ calculated from progeny genotype arrays for three subpopulations and for data pooled over subpopulations. Standard errors are in parentheses. Significance of differences from $t=1.0$ are shown. ${ }^{*} P<0.05$

\begin{tabular}{lcccccc}
\hline \multirow{2}{*}{ Subpopulation } & \multicolumn{7}{l}{ Locus } & & \multicolumn{2}{c}{$\begin{array}{l}\text { Mean over } \\
\text { loci }\end{array}$} & MDH1 & MDH2 & ADH & GOT & Multilocus \\
\cline { 2 - 5 } 1 & $1.04^{*}$ & 1.03 & 1.07 & 0.89 & 1.01 & 0.94 \\
& $(0.01)$ & $(0.07)$ & $(0.07)$ & $(0.06)$ & & $(0.05)$ \\
2 & 0.93 & 0.90 & 0.96 & 0.87 & 0.92 & 0.93 \\
3 & $(0.11)$ & $(0.07)$ & $(0.06)$ & $(0.07)$ & & $(0.04)$ \\
Mean over & 0.95 & $1.12^{*}$ & 1.02 & 1.03 & 1.03 & 1.02 \\
subpopulations & $(0.10)$ & $(0.06)$ & $(0.07)$ & $(0.08)$ & & $(0.04)$ \\
Pooled & 0.97 & 1.02 & 1.02 & 0.93 & 0.98 & 0.96 \\
& 0.96 & 1.05 & 1.00 & $0.91^{*}$ & 0.98 & 0.97 \\
& $(0.07)$ & $(0.04)$ & $(0.04)$ & $(0.04)$ & & $(0.03)$ \\
\hline
\end{tabular}

single locus outcrossing rates for each allozyme marker and subpopulation (Brown et al., 1975). Values of the outcrossing rate do not differ significantly from $t=1 \cdot 0$, random mating, except for MDH1 subpopulation 1, MDH2 subpopulation 3 and the pooled estimate of GOT (table 1). Pooling of data over subpopulations imparts only a slight downward bias to the estimate of $t$. This suggests that there is little genetic differentiation among the three subpopulations at the marker loci (Shaw et al., 1981; Ennos and Clegg, 1982).

Multilocus estimates of $t$ were calculated for each subpopulation and the total population using data for the three unlinked loci MDH2, ADH and GOT (Shaw et al., 1981). Despite low standard errors, no significant deviation from $t_{3}=1 \cdot 0$, random outcrossing, was detected. These independent estimates of outcrossing rate confirm the results of incompatability studies and show that no significant level of self-fertilisation is occurring within the $C$. cristatus population.

\section{(iii) Genetic Differentiation among subpopulations}

Table 2 gives the frequency of the faster migrating allele at each allozyme locus for the three adult subpopulations and total population. For three of the four loci significant heterogeneity in allele frequency is found among subpopulations $(P<$ $0.05)$, though the magnitude of differences in frequency is not large.

Frequencies of these same alleles in the pollen pool encountered by each subpopulation are given in table 2 for comparison. These values and their standard errors were estimated from progeny

Table 2 Adult and pollen allele frequencies for four allozyme loci in three sub-populations and for data pooled over subpopulations. Standard errors are in parentheses. In comparisons among subpopulations allele frequencies followed by a common letter do not differ significantly at $P<0.05$. Significant differences between pollen and adult allele frequencies are also shown

\begin{tabular}{|c|c|c|c|c|c|c|c|c|}
\hline \multirow[b]{3}{*}{ Subpopulation } & \multicolumn{8}{|l|}{ Locus } \\
\hline & \multicolumn{2}{|l|}{ MD1 } & \multicolumn{2}{|l|}{$\mathrm{MDH} 2$} & \multicolumn{2}{|l|}{$\mathrm{ADH}$} & \multicolumn{2}{|l|}{ GOT } \\
\hline & Adult & Pollen & Adult & Pollen & Adult & Pollen & Adult & Pollen \\
\hline 1 & $\begin{array}{c}0.985 a \\
(0.009)\end{array}$ & $\begin{array}{c}0.981 \mathrm{a} \\
(0.006)\end{array}$ & $\begin{array}{c}0.677 a \\
(0.033)\end{array}$ & $\begin{array}{c}0.601 a \\
(0.025)\end{array}$ & $\begin{array}{c}0.742 a \\
(0.031)\end{array}$ & $\begin{array}{c}0.760 a \\
(0.019)\end{array}$ & $\begin{array}{c}0.354 a \\
(0.034)\end{array}$ & $\begin{array}{r}0.296 a \\
(0.025)\end{array}$ \\
\hline 2 & $\begin{array}{l}0.964 \mathrm{ab} \\
(0.013)\end{array}$ & $\begin{array}{l}0.953 \mathrm{ab} \\
(0.019)\end{array}$ & $\begin{array}{c}0.663 \mathrm{a} \\
(0.034)\end{array}$ & $\begin{array}{c}0.559 \mathrm{a}^{*} \\
(0.031)\end{array}$ & $\begin{array}{c}0.704 a \\
(0.033)\end{array}$ & $\begin{array}{c}0.753 a \\
(0.023)\end{array}$ & $\begin{array}{c}0.240 \mathrm{~b} \\
(0.031)\end{array}$ & $\begin{array}{r}0.264 a \\
(0.025)\end{array}$ \\
\hline 3 & $\begin{array}{c}0.931 b \\
(0.018)\end{array}$ & $\begin{array}{c}0.952 b \\
(0.011)\end{array}$ & $\begin{array}{c}0.537 b \\
(0.036)\end{array}$ & $\begin{array}{c}0.615 a \\
(0.022)\end{array}$ & $\begin{array}{c}0.774 a \\
(0.031)\end{array}$ & $\begin{array}{c}0.797 a \\
(0.020)\end{array}$ & $\begin{array}{c}0.362 \mathrm{a} \\
(0.035)\end{array}$ & $\begin{array}{r}0.326 a \\
(0.024)\end{array}$ \\
\hline Pooled & $\begin{array}{c}0.960 \\
(0.008)\end{array}$ & $\begin{array}{c}0.962 \\
(0.005)\end{array}$ & $\begin{array}{c}0.627 \\
(0.020)\end{array}$ & $\begin{array}{c}0.603 \\
(0.013)\end{array}$ & $\begin{array}{c}0.740 \\
(0.018)\end{array}$ & $\begin{array}{c}0.770 \\
(0.012)\end{array}$ & $\begin{array}{c}0.318 \\
(0.019)\end{array}$ & $\begin{array}{c}0.298 \\
(0.014)\end{array}$ \\
\hline
\end{tabular}

$* P<0 \cdot 05$. 
genotype arrays by the method of Brown et al. (1975). Differences in allele frequency between adult and pollen pool subpopulations are only significant in one case out of 12 at $P<0.05$. Heterogeneity in pollen pool frequencies among subpopulations is only significant for one locus, MDH1 $(P<0.05)$. This suggests lower genetic differentiation among pollen than among adult subpopulations.

In order to quantify the extent of genetic divergence among subpopulations $G_{S T}$ (the expected deficit of heterozygotes caused by subpopulation differentiation) was calculated for adults and pollen pools (Nei, 1973; table 3 ). Values of $G_{S T}$ both for adults and pollen pools are extremely low when compared with estimates for inbreeding and insect pollinated plants (Brown, 1979), indicating weak subpopulation differentiation. The mean value of $G_{S T}$ for pollen pool subpopulations is less than a quarter of its value for adult subpopulations. This suggests the breakdown of genetic differentiation through pollen flow.

Table 3 Values of $G_{S T}(\%)$ measuring degree of genetic differentiation among adult and pollen pool subpopulations at four allozyme loci (Nei 1973)

\begin{tabular}{llllll}
\hline \multirow{5}{*}{} & \multicolumn{2}{l}{ Locus } & & & \\
\cline { 2 - 6 } & MDH1 & MDH2 & ADH & GOT & Mean \\
\hline Adults & 0.96 & 1.74 & 0.42 & 1.45 & 1.14 \\
Pollen & 0.36 & 0.23 & 0.23 & 0.31 & 0.28 \\
\hline
\end{tabular}

\section{(iv) Genotypic structure of adult population.}

Table 4 gives inbreeding coefficients within subpopulations $\left(F_{1 s}\right)$ and inbreeding coefficients within the total populations $\left(F_{1 T}\right)$ together with their standard errors as estimated for each allozyme locus. Values of both $F_{1 S}$ and $F_{1 T}$ lie very close to zero. Significant negative values of $F$ for locus MDH1 arise from the absence of a single rare homozygous individual which gives a spurious significance to the results. The only other significant deviation from $F=0$ is for MDH2 in subpopulations 3 . Overall there is no evidence for significant inbreeding either within the subpopulations or within the total population of adults.

Multilocus genotypic structure has been investigated by calculating gametic disequilibrium $D$ and its standard error between pairs of loci using progeny genotype data (Brown, 1975). Measures of $D$ within subpopulations have not been calculated for MDH1 because of the low
Table 4 Inbreeding coefficients for adults within subpopulations $\left(F_{I S}\right)$ and within the total population $\left(F_{I T}\right)$. Standard errors are in parentheses. significance of differences from $F=0$ are shown

\begin{tabular}{|c|c|c|c|c|}
\hline \multirow[b]{2}{*}{ Subpopulation } & \multicolumn{4}{|l|}{ Locus } \\
\hline & MDH1 $\mathrm{MDH} 2$ & $\mathrm{ADH}$ & GOT & Mean \\
\hline 1 & $\begin{array}{cc}-0.015 & -0.076 \\
(0.010) & (0.098)\end{array}$ & $\begin{array}{l}-0.083 \\
(0.094)\end{array}$ & $\begin{array}{c}-0.061 \\
(0.099)\end{array}$ & -0.059 \\
\hline 2 & $\begin{array}{cc}-0.037 \dagger & -0.005 \\
(0.014) & (0.101)\end{array}$ & $\begin{array}{l}-0.013 \\
(0.094)\end{array}$ & $\begin{array}{c}0 \cdot 188 \\
(0 \cdot 109)\end{array}$ & 0.033 \\
\hline 3 & $\begin{array}{rr}-0.074^{\dagger} & 0.208^{*} \\
(0.020) & (0.101)\end{array}$ & $\begin{array}{c}0.139 \\
(0.112)\end{array}$ & $\begin{array}{c}-0.014 \\
(0.103)\end{array}$ & 0.065 \\
\hline Mean $F_{i S}$ & $-0 \cdot 042$ & 0.015 & 0.038 & 0.013 \\
\hline$F_{I I}$ & $\begin{array}{cc}-0.041 \dagger & 0.067 \\
(0.009) & (0.059)\end{array}$ & $\begin{array}{c}-0.030 \\
(0.058)\end{array}$ & $\begin{array}{c}0.041 \\
(0.059)\end{array}$ & 0.009 \\
\hline
\end{tabular}

* $P<0.05$.

$+P<0.001$.

numbers of rare homozygotes at this locus. None of the estimates of $D$ differ from zero, even for the loosely linked $\mathrm{MDH} 1$ and $\mathrm{MDH} 2$ (table 5). This is the situation of gametic equilibrium expected under random mating when no epistatic interactions occur between the loci involved (Hedrick et al., 1978).

\section{DISCUSSION}

Earlier work on pollen-stigma interaction has indicated that $C$. cristatus possesses a gametophytic multilocus self-incompatibility system (Weimarck, 1968). In the population studied here uniformly high levels of self-incompatibility were found. There is no evidence for segregation of selfcompatibility or pseudo-self-compatibility among the 147 genotypes tested. This contrasts with previous work which suggested that segregation for self-compatibility may be common in $C$. cristatus (Beddows, 1931). In the self-incompatible grass Lolium multiflorum Allard et al. (1977) reported that up to 30 per cent of seeds were set by selfpollination and there has been speculation that it may be common to find self-compatible individuals within populations of predominantly self-incompatible species (Maynard Smith, 1978). The results reported here do not bear out such ideas, at least for this population of $C$. cristatus.

Estimates of outcrossing rate using allozyme markers give an overall outcrossing estimate of $t=0.98$, identical to that predicted from a study of the incompatibility system. There is again no 
Table 5 Estimates of gametic disequilibrium $D$ between four allozyme loci in three subpopulations together with estimates for pooled data. Standard errors in parentheses

\begin{tabular}{lccllll}
\hline \multirow{2}{*}{ Subpopulation } & \multicolumn{1}{l}{ Loci } & \multicolumn{1}{l}{$l$} & \\
\cline { 2 - 7 } 1 & MDH2/ADH & MDH2/GOT & MDH2/MDH1 & ADH/GOT & ADH/MDH1 & GOT/MDH1 \\
\hline & 0.010 & 0.011 & - & -0.014 & - & - \\
2 & $(0.010)$ & $(0.010)$ & - & $(0.010)$ & - & - \\
3 & 0.017 & 0.005 & - & 0.001 & - & - \\
Pooled & $(0.010)$ & $(0.009)$ & - & $(0.008)$ & - & - \\
& -0.006 & -0.004 & - & $(0.012)$ & - & - \\
& $(0.008)$ & $(0.010)$ & - & $(0.008)$ & - & - \\
& 0.005 & 0.003 & 0.002 & $(0.001)$ & 0.001 & -0.002 \\
& $(0.005)$ & $(0.006)$ & $(0.002)$ & $(0.005)$ & $(0.002)$ & $(0.002)$ \\
\hline
\end{tabular}

evidence for significant self-pollination in the population. Amalgamation of data from three subpopulations imparts little downward bias to the estimate of outcrossing rate. Such a result is expected when the degree of genetic differentiation at marker loci among subpopulations is very low (Shaw and Allard, 1981; Ennos and Clegg, 1982). The absolute value of genetic differentiation among adult subpopulations $\left(G_{S T}=1.4\right.$ per cent $)$ lies at the lower end of the range reported by Brown (1979) for plant populations. It is similar to the only other figure available for an outcrossing, wind pollinated grass, Lolium multiflorum (Mitton et al., quoted in Brown, 1979). This extremely low value for genetic differentiation at allozyme loci is probably due to substantial gene flow within the population through wind dispersal of pollen. Large amounts of gene flow prevent genetic drift occurring independently in different areas of the same population (Wright, 1943; Rohlf and Schnell, 1971; Turner et al., 1982; Crawford, 1984).

The idea that pollen dispersal is extensive is borne out by a comparison between $G_{S T}$ values for adults and pollen pools. Spatial genetic differentiation is four times lower among pollen pool subpopulations than among adults sampled from the same areas. Pollen flow reduces genetic differentiation substantially. The pollen pool is not, however, completely spatially homogeneous, for significant heterogeneity in allele frequency at locus MDH 1 is present. Additional tests for genetic heterogeneity can be made by comparing progeny genotype frequencies among maternal individuals of the same homozygous genotype (Brown et al., 1975). Any differences in progeny genotype frequencies among these maternal genotypes must be due to heterogeneity in the pollen pool sampled when producing progeny. Significant heterogeneity in progeny genotype frequency was found for $\mathrm{MDH} 2$ and GOT in subpopulation $1, \mathrm{ADH}$ in subpopulation 2, and $\mathrm{MDH} 2$ and GOT when all subpopulations were combined $(P<0.05$ in all cases, table 6 ). Therefore at the scale of the pollen pool encountered by a single individual, significant genetic heterogeneity exists. This could arise not only through very local spatial genetic differentiation, but also as a result of temporal changes in pollen pool allele frequencies throughout the flowering season.

Table 6 Significance of heterogeneity among progeny genotype arrays of homozygous maternal genotypes for 3 allozyme loci

\begin{tabular}{|c|c|c|c|c|c|c|}
\hline \multirow[b]{3}{*}{ Subpopulations } & \multicolumn{6}{|c|}{ Locus } \\
\hline & \multicolumn{2}{|c|}{$\mathrm{MDH} 2$} & \multicolumn{2}{|c|}{$\mathrm{ADH}$} & \multicolumn{2}{|c|}{ GOT } \\
\hline & df & $\chi^{2}$ & $\mathrm{df}$ & $x^{2}$ & $\mathrm{df}$ & $x^{2}$ \\
\hline 1 & 24 & $41 \cdot 3^{*}$ & 24 & $18 \cdot 5$ & 24 & $37 \cdot 4^{*}$ \\
\hline 2 & 27 & $35 \cdot 9$ & 27 & $42 \cdot 3^{*}$ & 36 & $41 \cdot 1$ \\
\hline 3 & 26 & $32 \cdot 2$ & 32 & $36 \cdot 2$ & 24 & $31 \cdot 6$ \\
\hline Pooled & 77 & $109 \cdot 5^{*}$ & 83 & $97 \cdot 0$ & 84 & $110 \cdot 1^{*}$ \\
\hline
\end{tabular}

${ }^{*} P<0.05$.

Differences in allele frequency between adults and the pollen pool were non-significant. There is no evidence for the action of natural selection on any of the allozyme variants during the transition from adult plants to pollen successful in fertilisation. This result is of some importance since we are assuming that the differentiation which we are observing at allozyme loci represents the results of interaction between gene flow and genetic drift in the absence of selection.

Genotypic structure of the $C$. cristatus population conforms to expectations for a random mating 
population with extensive intrapopulation gene flow. Inbreeding coefficients are not significantly different from zero, and linkage disequilibrium, even between the loosely linked loci MDHl and MDH2 is negligible. This situation can be contrasted with that for inbreeding grasses where highly significant gametic disequilibrium is commonly detected in natural populations (Allard et al., 1972; Brown et al., 1977).

We can conclude that this population of $C$. cristatus is uniformly self-incompatible, shows random mating, minimal spatial heterogeneity of allozyme frequencies and substantial gene flow via pollen. If spatial genetic differentiation were detected in a population of this type, this would provide strong circumstantial evidence that natural selection had brought about the differentiation. Its adaptive nature could only be confirmed, however, by the use of appropriate reciprocal transplant experiments (Davies and Snaydon, 1976, Silander, 1979).

Acknowledgements I am grateful to the University of Newcastle Research Fund for a grant towards the cost of chemicals

\section{REFERENCES}

ALLARD, R. W., BABBEL, (;. R, (I.FGG, M. T. AND KAHLER, A I. 1972. Evidence for coadaptationin Avena barbata. Proc: Natl. Acad. Sci. U.S.A., 69, 3043-3048.

ALLARD, R. W., KAHLER, A. L. AND CLEGG, M. T. 1977. Estimation of mating cycle components of selection in plants. In Christiansen, F. B. and Fenchel, T. M. (eds.) Measuring Selection in Natural Populations, Springer-Verlag, Berlin, pp. 1-19.

BEDDOWS, A. R. 1931. Seed setting and flowering in various grasses. Welsh Plant Breeding Station Bulletin, Series H, No. 12 , pp. $51-53$.

BROWN, A. H. D. 1975. Sample sizes required to detect linkage Jisequilibrium between two or three loci. Theor. Pop. Biol., $8,184-201$.

BROWN, A. H. D. 1979. Enzyme polymorphism in plant populations. Theor. Pop. Biol., 15, 1-42.

BROWN, A. H. D., MATHESON, A. C. AND ELDRIDGE, K. G. 1975. Estimation of the mating system of Eucalyptus obliqua L'Herit. using allozyme polymorphisms. Aust. J. Bot., 23, 931-949.
BROWN, A. H. I). NEVO. E. AND ZOHARY, D. 1977. Association of alleles at esterase 1 - $\mathrm{ci}$ in wild barley Hordeum spontaneum. Nature, 268,430-431.

CRAWFORD, I. J. 1984. What is a population? In Shorrocks, B. (ed.) Evolutionary Ecology, Blackwell, Oxford, pp. 135173

DAVIES, M. S. AN1) SNAYDON, R. W. 1976. Rapid population differentiation in a mosaic environment III. Coefficients of selection. Heredity, 36, 59-66.

ENNOS, R. A. 1985. Allozyme variation, linkage and duplication in the perennial grass Cynosurus cristatus. J. Hered. (in press).

ENNOS, R. A. AND C1.:GG, M. T. 1982. Effect of population substructuring on estimates of outcrossing rate in plant populations. Heredity, 48, 283-292.

GLEAVFS, J. T. 1973. Gene flow mediated by wind-borne pollen. Heredity, 31, 355-366.

HEDRIC.K, P., JAIN, S. ANI) HOI.ISI:N, L. 1978. Multilocus systems in evolution. Evol. Biol. 11, 101-184.

JAIN, S. K. AND BRADSHAW, A. D. 1966. Evolutionary divergence among adjacent plant populations. I. The evidence and its theoretical analysis. Heredity, 21, 407-441.

MAYNARD SMITH, J. 1978. The Evolution of Sex, Cambridge University Press, Cambridge, pp. 127-128.

MCNEILLY, T. 1968. Evolution in closely adjacent plant populations III. Agrostis tenuis on a small copper mine. Heredity, 23, 205-218.

NEI, M. 1973. Analysis of gene diversity in subdivided populations. Proc. Natl. Acad. Sci. U.S.A., 70, 3321-3323.

ROHLF, F, J. AND SCHNELL, G. D. 1971. An investigation of the isolation-by-distance model. Amer. Nat., 105, 295-324.

SCHAAL, B. A. 1974. Isolation by distance in Liatris cylindracea. Nature, 252, 703.

SHAW, D. V. AND ALLARD, R. W. 1981. Analysis of mating system parameters and population structure in Douglas fir using single-locus and multi-locus methods. In Proceedings of the Symposium on Isozymes of North American Forest Trees and Forest Insects. P.S.W. Range Exp. Stn. Gen. Tech. Rep. PSW-48.

SHAW, D. V., KAHLER, A. I. AND ALLARD, R. W. 1981. A multilocus estimator of mating system parameters in plant populations. Proc. Natl. Acad. Sci. U.S.A., 78, 1298-1302.

SILANDER, J. A. 1979. Microevolution and clone structure in Spartina patens. Science, 203, 658-660.

SNAYDON, R. W. AND DAVIES M. S. 1972. Rapid population differentiation in a mosaic environment. II. Morphological variation in Anthoxanthum odoratum. Evolution, 26, 390 405.

TURNER, M. E., STEPHENS, J. C. AND ANIJERSON, W. W. 1982. Homozygosity and patch structure in plant populations as a result of nearest-neighbor pollination. Proc. Nall. Acad. Sci. U.S.A., 79, 203-207.

WEIMARCK, A. 1968. Self-incompatability in the Graminae. Hereditas, 60, 157-166.

WRICiHT, S. 1943. Isolation by distance. Genetics, 28, 114-138. 